\title{
Fluorine containing amino acids: Synthesis and peptide coupling of amino acids containing the all-cis tetrafluorocyclohexyl motif
}

\author{
Mohammed Salah Ayoup, ${ }^{\dagger,}$ David B. Cordes, ${ }^{\dagger}$ Alexandra M. Z. Slawin, ${ }^{\dagger}$ and David O’Hagan ${ }^{\dagger *}$ \\ ${ }^{\dagger}$ School of Chemistry, University of St Andrews, North Haugh, St Andrews, KY16 9ST, UK. \\ Department of Chemistry, Faculty of Science, P.B 426 Ibrahimia, Alexandria University, Egypt. \\ Corresponding author e.mail do1@st-andrews.ac.uk
}

\begin{abstract}
A synthesis of two $(S)$-phenylalanine derivatives is described which have the allcis, 2,3,5,6-tetrafluorocyclohexyl motif attached to the aromatic ring at the meta and para positions; the para substituted isomer is elaborated into illustrative dipeptides via the free amine and carboxylate respectively demonstrating its utility as a novel amino acid for peptide synthesis and offering a vehicle for incorporation of this unique and facially polarized ring system into bioactive compounds.
\end{abstract}

Our laboratory has developed an interest in preparing selectively fluorinated cyclohexane rings, with no more than one fluorine on each carbon and where at least two of the C-F bond lie 1,3diaxial to each other. ${ }^{1}$ Such a diaxial arrangement generates two parallel C-F bonds, and as a consequence of the high polarity of this bond, the arrangement differentially polarises the two faces of the cyclohexane. This creates a large molecular dipole moment and offers unique polar hydrophobic properties to the motif. In order to hold this conformation in the ground state it has been necessary to prepare cyclohexanes with at least four C-F bonds and all with the same 'up' stereochemistry. This was first illustrated by the synthesis of tetrafluorocyclohexanes $\mathbf{1}^{1 \mathrm{a}}$ and $\mathbf{2} .^{1 \mathrm{~b}}$ for these compounds there are always four fluorines on one face of the ring, with two C-F bonds axial and the other two equatorial, even after a ring flip. 

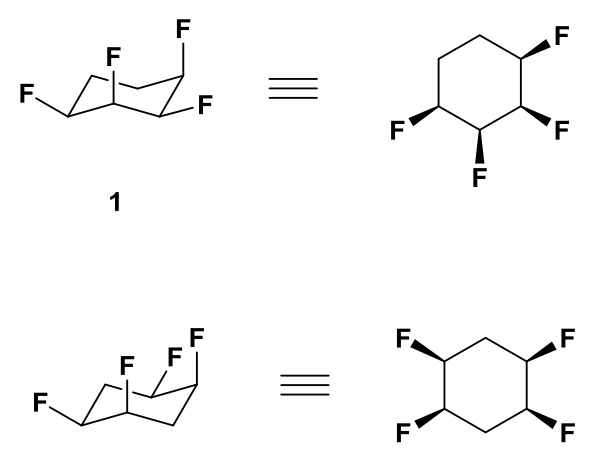

2

Fig. 1 All-cis tetrafluorocyclohexane isomers $\mathbf{1}$ and $\mathbf{2}$.

Of note is the high molecular dipole moments of $\mathbf{1}$ and 2 (4.9 D and 5.2D respectively $)^{1 \mathrm{a}, 1 \mathrm{~b}}$. Crystallography reveals that these molecules have a tendency to stack one on top of another consistent with electrostatic compensation in the solid state. In solution the axial hydrogens on the non-fluorous face of the rings display anisotropic shifts by ${ }^{1} \mathrm{H}-\mathrm{NMR}$ when the solvent is changed from dichloromethane to toluene, consistent with the aromatic solvent associating with the electropositive face of the cyclohexane. The interesting properties of these ring systems have challenged us to find relatively accessible building blocks such that they can be incorporated as a substituent in a building block fir utility in a diversity of research programmes. To that end we recently described a method for the preparative synthesis of all-cis 3-phenyl-1,2,4,5tetrafluorocyclohexane 3 . $^{1 \mathrm{c}, 1 \mathrm{~d}}$ This compound is amenable to a range of electrophilic aromatic substitution reactions, and some of these transformations have recently been described. ${ }^{\text {c }}$ Selectively fluorinated amino acids have been the focus of much attention ${ }^{2}$ and we were attracted by the prospect of placing this motif into an amino acid as a building block for its inclusion into designer peptides. In this Communication we report the synthesis of the new amino acids $(S)$-11 and $(S)-\mathbf{1 2}$ carrying the all-cis 1,2,4,5,-tetrafluorocyclohexane ring system. One of these $(S)$-phenylalanine derivatives $\mathbf{1 1}$ is differentially protected for regioselective elaboration at the carboxy and N-termini to generate dipetides with $(S)$-phenylalanine, and also an amide to isopenicillin-N is also prepared.

Our approach to the amino acids came from an initial iodination reaction of $\mathbf{3}$ in a periodic acid protocol $^{3}$. This resulted in a mixture of ortho/meta/para isomers 4, 5 and $\mathbf{6}$ and diiodo 7 in a ratio of 1:5:15:4 respectively. 


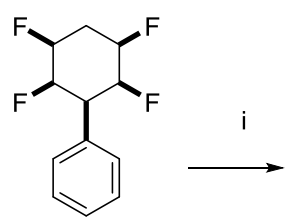

3

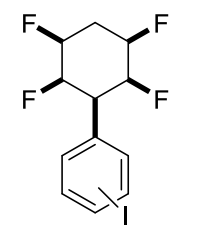

$4 / 5 / 6$

$\mathrm{o} / \mathrm{m} / \mathrm{p}$

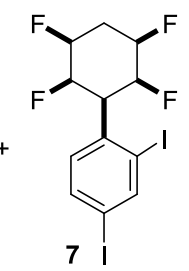

Scheme 1 Products of the iodination of 3. i. $\mathrm{HIO}_{4} \cdot 2 \mathrm{H}_{2} \mathrm{O}(50 \%), \mathrm{AcOH}, \mathrm{H}_{2} \mathrm{SO}_{4}, \mathrm{I}_{2}, \mathrm{H}_{2} \mathrm{O}, 70{ }^{\circ} \mathrm{C} 24 \mathrm{~h}, 92 \%$.

Chromatography readily removed the minor ortho isomer 4 and the diiodo product 7 respectively from the major meta/para products $\mathbf{5 / 6}$, however these latter two isomers were proved inseparable. Iodides 5 and $\mathbf{6}$ were taken as a mixture (ratio 1:3 respectively) and were subjected to Jackson's methodology ${ }^{4-6}$ for amino acid synthesis via Zn homoenolate coupling with the protected $(R)$-iodoalanine $\mathbf{8}^{5,6}$ as illustrated in Scheme 2. This resulted in an excellent conversion to the fully protected amino acid isomers $\mathbf{9}$ and 10, which were readily separated from each other by chromatography. When treated separately, deprotection ${ }^{7}$ of the isomers gave the individual free amino acids $(S)$-11 and $(S)$-12. A crystal of $(S)$-11 proved amenable to X-ray analysis and the structure is shown in Figure 2. The structure has the expected 1,3-diaxial arrangement of two C-F bonds, which imparts polarity to this ring motif. 

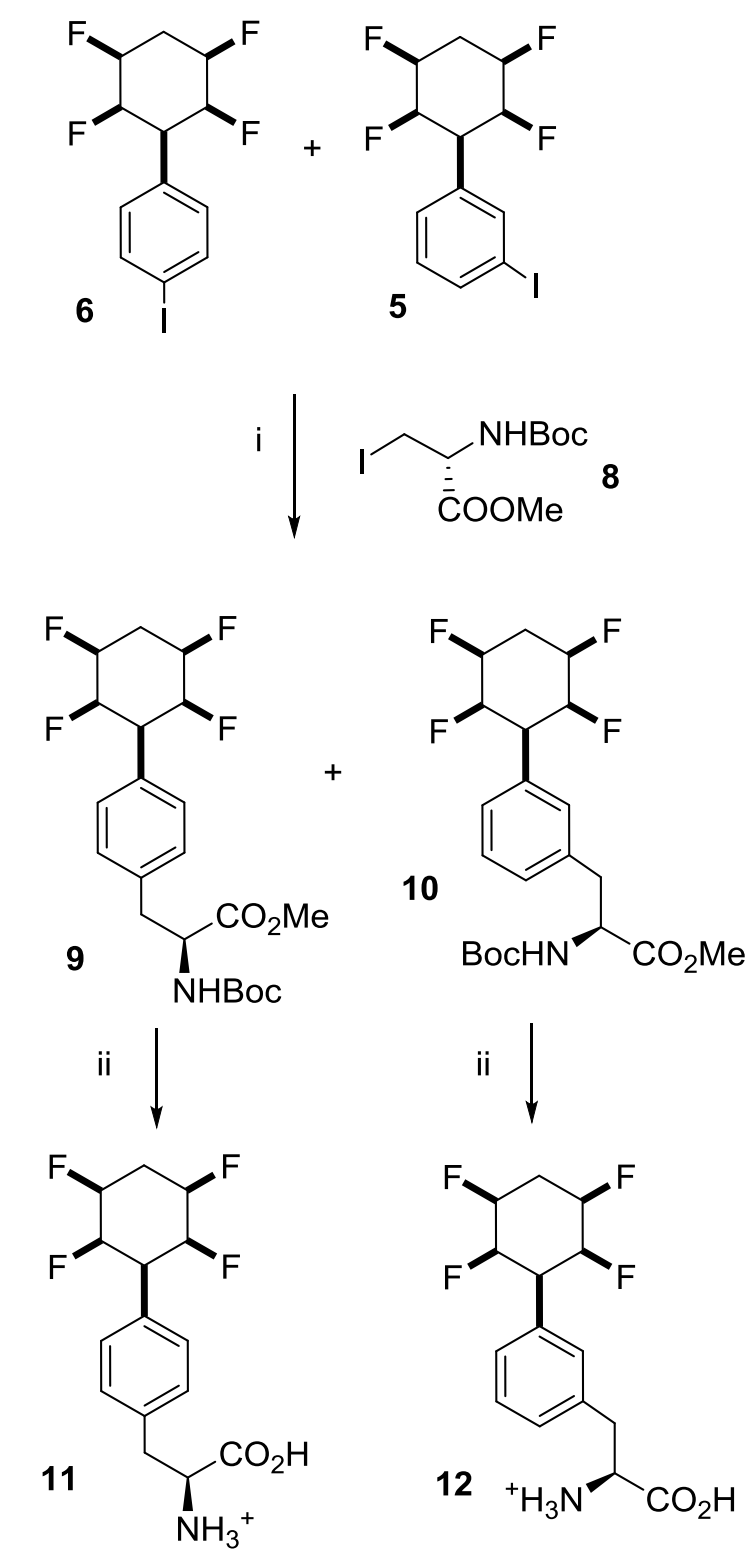

Scheme 2 Synthesis of amino acids 11 and 12: i. $\mathrm{Zn}, \mathrm{I}_{2}, \mathrm{DMF}, 8, \mathrm{Pd}_{2}(\mathrm{dba})_{3}, \mathrm{SPhos}, 85 \%$; ii. $6 \mathrm{M} \mathrm{HCl}$ in 1,4-dioxane, $70{ }^{\circ} \mathrm{C}, 48 \mathrm{~h}, 100 \%$. 


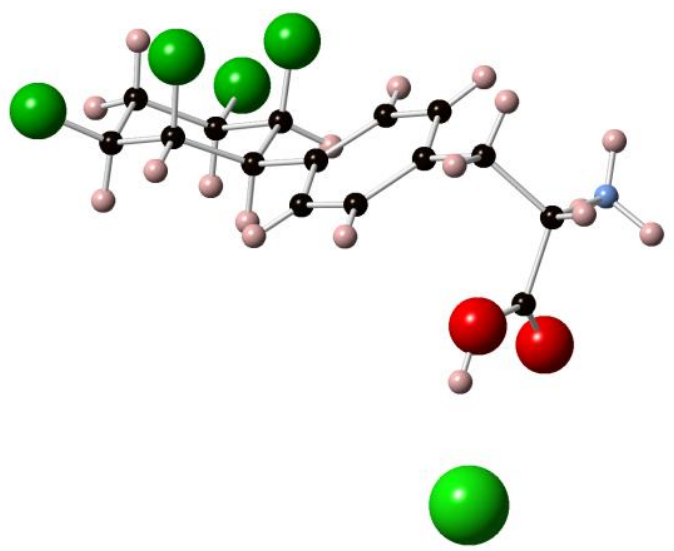

Figure $2 \mathrm{X}$-Ray structure of amino acid $(S)-\mathbf{1 1}$ as a $\mathrm{HCl}$ salt. (Structure data deposited at the Cambridge Crystallographic Data Centre, CCDC No $=1057152$ ).

In order to explore further elaboration of a tetrafluorocyclohexyl amino acid, peptide coupling of the hydrochloride salt of $(S)$-11 via the carboxylate, was explored. Thus $N$-Boc protection using di-t-butyldicarbonate in THF gave $N$-Boc $\mathbf{1 3}^{8}$ which could be coupled with L-phenylalanine$\mathrm{OMe}^{9}$ to generate dipeptide $\mathbf{1 4}$ in good yield.

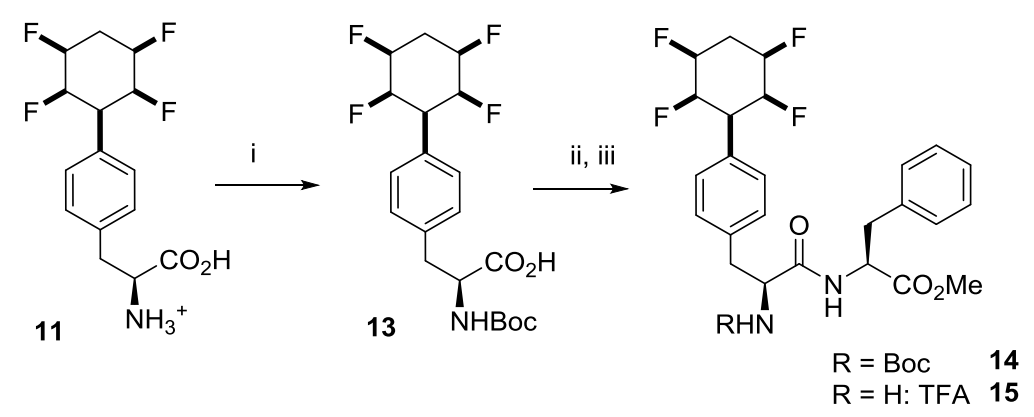

Scheme $3 C$-Terminal coupling to generate dipeptide 14 and 15 i. $\mathrm{NaHCO}_{3}, \mathrm{THF} / \mathrm{H}_{2} \mathrm{O}(1: 1),(\mathrm{Boc})_{2} \mathrm{O}, \mathrm{rt}$, overnight $93 \%$; ii. EDCI, HOBt, NMM, DMF, rt, overnight 87 \%; iii. TFA, DCM (1:4), rt, 4h, $94 \%$.

$N$-Boc deprotection with trifluoroacetic acid ${ }^{10}$ resulted in the dipeptide methyl ester $\mathbf{1 5}$ as its trifluoroacetate salt. This sequence is summarized in Scheme 3.

Complementary $N$-terminal coupling was achieved by selective deprotection ${ }^{11,12}$ of amino acid $\mathbf{1 0}$ as illustrated in Scheme 4. Treatment of $\mathbf{1 0}$ with $4 \mathrm{M} \mathrm{HCl}$ in ethyl acetate triggered $N$-Boc deprotection to afford the methyl ester amine hydrochloride salt $\mathbf{1 6}$ in quantitative yield. This intermediate was then coupled with either $N$-Boc-L-Phe- $\mathrm{OH}^{9}$ or $N$-Fmoc $\mathrm{L}-\mathrm{Phe}-\mathrm{OH}^{13}$ to generate dipeptides 17 and 18 in good yields. Deprotection of 17 with TFA afforded dipeptide 
19a as its trifluoroacetate salt, or Fmoc deprotection of $\mathbf{1 8}$ with $10 \%$ diethylamine ${ }^{14}$ in DMF or $(20 \% \mathrm{v} / \mathrm{v})$ piperidine ${ }^{15}$ in DMF to afforded the free $\mathrm{NH}_{2}$ dipeptide of $\mathbf{1 9 b}$.
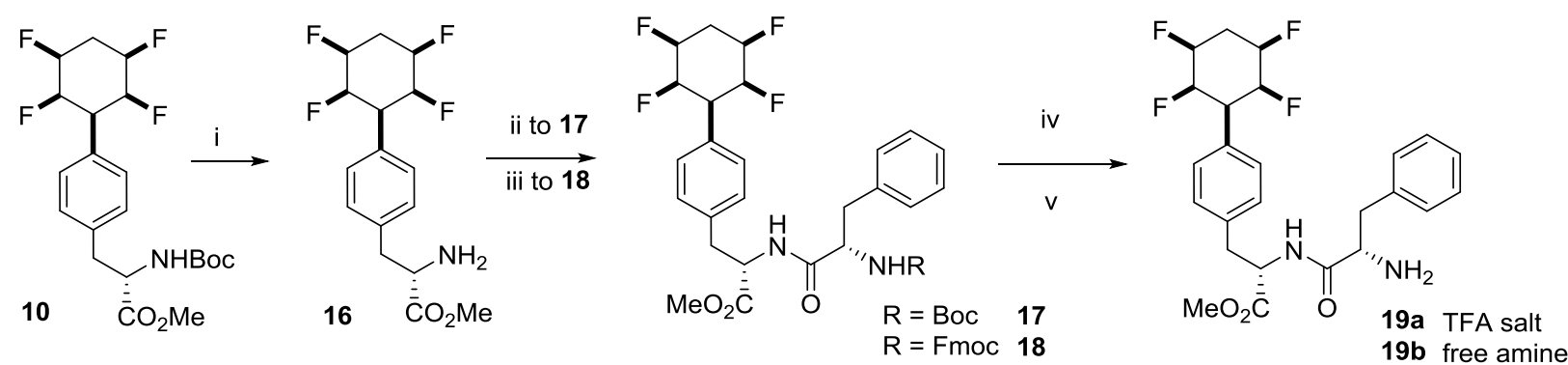

Scheme 4: $N$-terminal coupling of $\mathbf{1 6}$ to generate dipeptide 19; i. $4 \mathrm{M} \mathrm{HCl}$, EtOAc (1:1), rt, overnight, 100\%. ; ii. HOBt, HBTU, NMM, 6h, rt, 81 \%; iii. EDCI, HOBt, DMF, DIPEA, rt, overnight, 92 \%; iv. 17 TFA, DCM (1:4), rt, 4h, $89 \%$; v. 18 DEA, DMF, rt, 2h, $94 \%$, or piperidine in DMF (20\% v/v), rt, 2 h, $97 \%$.

To illustrate a level of elaboration of this amino acid moiety, a penicillin derivative was prepared as illustrated in Scheme 5. Thus coupling ${ }^{9}$ of $N$-Boc amino acid 13 with 6-aminopenicillinic acid (APA) benzyl ester $\mathbf{2 0}^{16}$, gave penicillin dipeptide 21 which could be partially deprotected (4 M $\mathrm{HCl}$ in dioxane $)^{17}$ to give the novel amino acid acylated penicillin 22 as its hydrochloride salt.
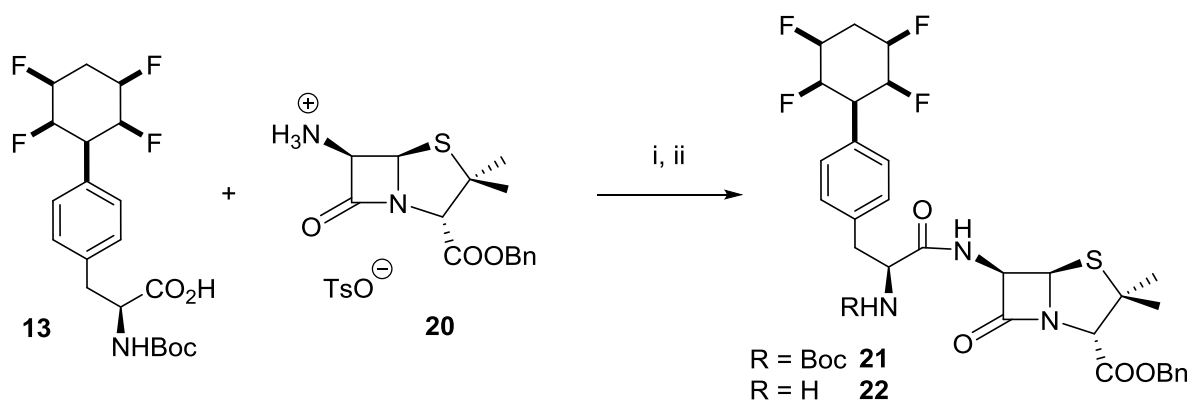

Scheme 5 Preparation of $N$-acylated penicillin derivatives 21 and 22. i. EDCI, HOBt, DMF, NMM, rt, overnight, $81 \%$; ii. $4 \mathrm{M} \mathrm{HCl}, 1,4$-Dioxane (1:1), 1 h, $83 \%$.

The tetrafluorocyclohexyl moiety is resistant to acidic conditions and transformations using trifluoroacetic acid and concentrated mineral acid are compatible with the ring system. The ring is also compatible with organic base deprotections such a $10 \%$ diethylamine. However attempts 
to mediate aqueous base hydrolysis of the ester moiety of $\mathbf{1 4}$ resulted in defluorination and complex product mixtures. Thus elaborations of protecting groups under those conditions are limiting. In conclusion, we have demonstrated the conversion of the tetrafluorophenylcyclohexane $\mathbf{3}$ into the amino acids $\mathbf{1 1}$ and $\mathbf{1 2}$ using Jackson's organozinc protocol. These are elaborated derivatives of L-phenylalanine, and present an unexplored polar hydrophobic moiety in an amino acid, amenable to inclusion in peptides. The amino acids were coupled to $(S)$-phenylalanine through both its $C$ and $N$ terminus, and one was coupled to isopenicillin- $N$ to demonstrate an elaboration to a relevant bioactive compound class. The tetrafluorocyclohexane moiety is compatible with acid mediated deprotection strategies, and organic bases, however the ring system is incompatible with aqueous base.

Acknowledgments: One of us (MA) thanks the Egyptian Government for a Scholarship and also we thank Professor Laila Fathy of the University of Alexandria, Egypt for her support. DO'H thanks the Royal Society for a Royal Society Wolfson Research Merit Award.

\section{References}

1. (a) A. J. Durie, A. M. Z. Slawin, T. Lebl, P. Kirsch, D. O’Hagan, Chem Commun., 2011, 47, 8265. (b) A. J. Durie, A. M. Z. Slawin, T. Lebl, P. Kirsch, D. O’Hagan, Chem. Commun., 2012, 48, 9643. (c) A. J. Durie, T. Fujiwara, N. Al-Maharik, A. M. Z. Slawin, D. O’Hagan, J. Org. Chem., 2014, 79, 8228. (d) A. J. Durie, T. Fujiwara, R. Cormanich, M. Bühl, A. M. Z. Slawin, D. O’Hagan, Chem. Eur. J., 2014, 20, 6259.

2. (a) V. Asante, J. Mortier, G. Wolber, B. Koksch, Amino Acids, 2014, 46, 2733. (b) L. Hunter, S. Butler, S. B. Ludbrock, Org. Biol. Chem., 2012, 10, 8911. (c) X-L. Qiu, F-L. Qing, Eur. J. Org. Chem., 2011, 3261. (d) Y-L. Liu, T-D. Shi, F. Zhou, X-L. Zhao, X. Wang, J. Zhou, Org. Lett., 2011, 13, 3826.

3. B. A. Hathaway, K. L. White, and M. E. McGill, Synth. Commun., 2007, 37, 3855.

4. R. F. W. Jackson, D. Turner, H. M. Block, Synlett., 1997, 7,789.

5. A. J. Ross, H. L. Lang, R. F. W. Jackson, J.Org. Chem., 2010, 75, 245.

6. A. J. Ross, F. Dreiocker, M. Schäfer, J. Oomens, A. J. H. M. Meijer, B. T. Pickup, R. F. W. Jackson, J. Org. Chem., 2011, 76, 1727.

7. C. W. Barfoot, J. E. Harvey, M. N. Kenworthy, J. P. Kilburn, M. Ahmed, R. J. K. Taylor, Tetrahedron, 2005, 61, 3403. 
8. D. M. Shendage, R. Fröhlich, G. Haufe, Org. Lett., 2004, 6, 3675.

9. C. Crauste, M. Froeyen, J. Anne, P. Herdewijn, Eur. J. Org. Chem., 2011, 3437.

10. G. W. Anderson, F. M. Callahan, J. Am. Chem. Soc., 1960, 82, 3359.

11. R. B. Merrifield, J. Am. Chem. Soc., 1963, 85, 2149.

12. R. B. Merrifield, Adv. Enzymol., 1969, 32, 221.

13. L. Carpino, H. Imazumi, A. El-Faham, F. J. Ferrer, C. Zhang, Y. Lee, B. M. Foxman, P. Henklein, C. Hanay, C. Mügge, H. Wenschuh, J. Klose, M. Beyermann, M. Bienert, Angew.Chem. Int. Ed., 2002, 41, 441.

14. C. D. Chang, M. Waki, M. Ahmad, J. Meienhofer, E.O. Lundell, J. D. Haug, Int. J. Peptide Protein Res., 1980, 15, 59-66.

15. F. Albericio, E. Nicolás, J. Rizo, E. Ruiz-Gayo, E. Pedroso, E. Giralt, Synthesis, 1990, 119.

16. M.S. Manhas, K. Gala, S. S. Bari, A. K. Bose, Synthesis, 1983, 549-552.

17. G. Han, M. Tamaki, V. J. Hruby, J. Peptide Res., 2001, 58, 338. 